\title{
Effect of Meloxicam on Pharmacokinetics of Long Acting Moxifloxacin in Goats
}

\author{
Kumari Anjana ${ }^{1}$, S.K. Mody ${ }^{2}$, R.K. Nirala ${ }^{*}$ and Archana Kumari ${ }^{3}$ \\ ${ }^{1}$ Department of Pharmacology and Toxicology, Bihar Veterinary College, Patna, India \\ ${ }^{2}$ Department of Pharmacology and Toxicology, S.K. Nagar, Dantiwada Agricutural University, \\ Gujrat, India \\ ${ }^{3}$ Indian Council of Medical Research (ICMR), IITR Lucknow, India \\ *Corresponding author
}

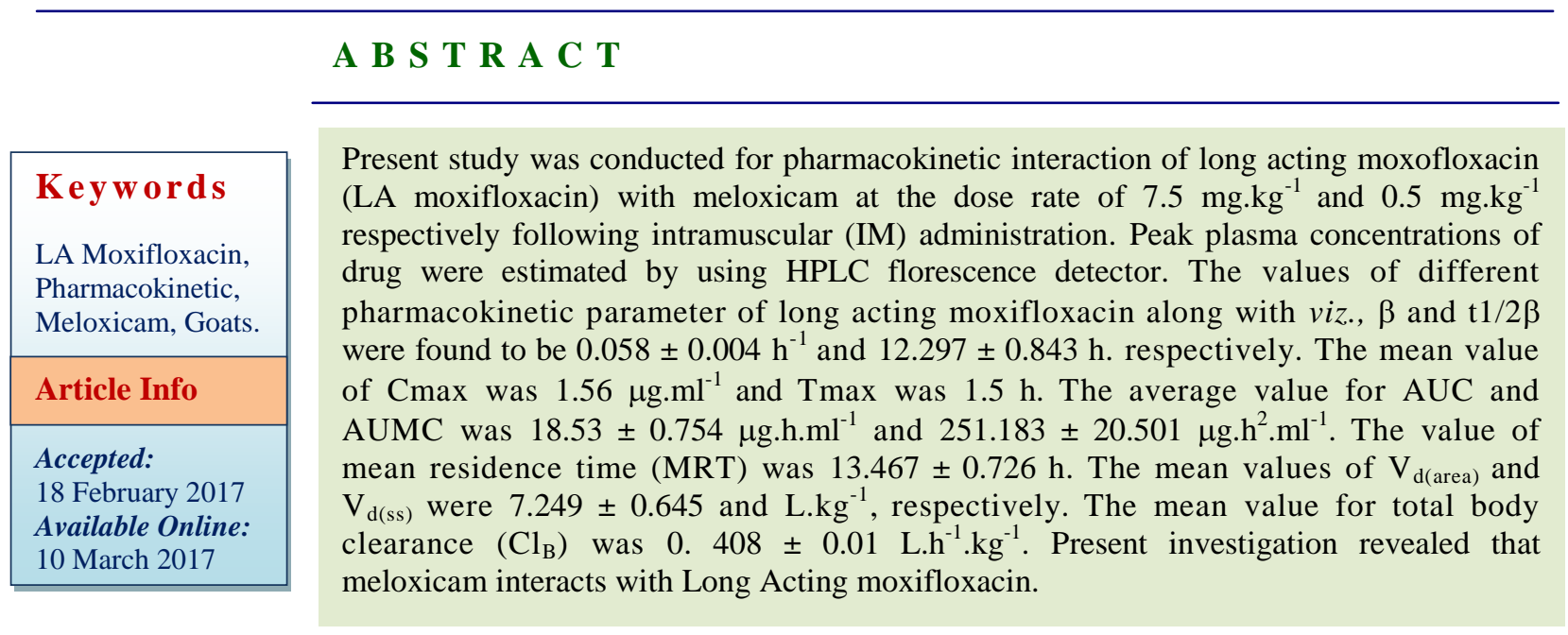

\section{Introduction}

Meloxicam, is most commonly used non steroidal anti inflammatory drug (NSAIDS) in veterinary practices. It is an enolic acid class non steroidal anti inflammatory drug preferentially inhibits inducible Cyclooxygenase-2(Cox-2) over Cox- 1and have anti inflammatory, analgesic and antipyretics activities (Euller-Ziegler and Velicitat, 2001). Moxifloxacin is a new 8methoxy quinolone, chemotherapeutic agent with broad spectrum of antibacterial activities against Gram-positive and Gram-negative bacteria, anaerobes and typical organism such as Mycoplasma and Chlamydia Spp (Sullivan et al., 1999 and Noel et al., 2005). It has the highest potency against Staphylococcus aureus, Staphylococcus epidermidis and also possess large volume distribution, low plasma protein binding and relatively low MICs against susceptible target microorganisms. Moxifloxacin is highly effective against Mycobacterium leprae, used for treatment of leprosy, it significantly kill microorganism upto $81 \%$ to $91 \%$ (Pardillo et al., 2008). The drug thus seems to be extremely useful in a variety of infections including those of urinary tract, respiratory tract, soft tissues, bones and joints. The combined use of 
antibiotics and NSAIDS is very common in Veterinary Practices (Deleforge et al., 1994). Concurrent use of Meloxicam alters the pharmcokinetics of certain drugs, like furosemide and levofloxacin (Muller et al., 1997; Dumka et al., 2008).

Pharmacokinetics of Moxifloxacin as well as Meloxicam investigated alone in different species but the effect of Meloxicam on Pharmacokinetics of LA Moxifloxacin has not been investigated in goats. Hence the objective of present investigation was to determine pharmacokinetic interaction of LA moxifloxacin along with meloxicam.

\section{Materials and Methods}

\section{Experimental animals}

Six healthy male Mehsana goats of body weight between $25-35 \mathrm{~kg}$ of 2-3 year of age were dewormed and acclimatized for 30 days in experimental animal shed before starting the experiment. They were maintained on concentrate, adequate green and dry fodder and ad libitum fresh water.

The experimental protocol was approved by Institutional Animal Ethical Committee and all the measures for welfare of experiment animals were taken as per committee for purpose of control and supervision on experiment on animal guideline.

\section{Drugs and chemicals}

Long acting Moxifloxacin (10\% moxifloxacin in solution with L-arginine, N-butyl alcohol and benzyl alcohol) injectable solution and moxifloxacin base powder were obtained from INTAS Animal health, Gujrat India water, acetonitrile and tetrabutyl ammonium hydrogen sulfate of HPLC grade were procured from S.D Fine Chem. Ltd Mumbai.

\section{Experimental design}

Six goats were administered long acting moxifloxacin at the dose rate of $7.5 \mathrm{mg} \mathrm{kg}^{-1}$ b.wt through intramuscular (i.m) in gluteal muscles. For pharmacokinetics study blood samples (approx $5 \mathrm{ml}$ ) were collected from each goat in heparin containing test tube with the help of an intravenous catheter (Venflon) fix into Jugular Vein at zero time before drug administration and at different time interval like 0.083 (5 min), 0.166 (10 $\mathrm{min}$ ), 0.5, 1, 2, 4, 8, 12, 24, 36, 48, 60, 72 and up to 96 h Post administration of drug. Plasma was separated after centrifugation of blood samples at 1660 revolutions per minute (rpm) for 10 minutes. The plasma samples were transferred to cryovials and stored at $-4^{\circ} \mathrm{C}$ until assayed. After two weeks of wash out period interaction study was performed in same animals for this long acting moxifloxacin were given dose @ $7.5 \mathrm{mg} \cdot \mathrm{kg}^{-1}$ b.wt. and meloxicam dose @ 0.5 mg.kg ${ }^{-1}$ body weight concomitantly at different body sites. Collection of blood samples at different time interval and preparation of plasma were as same as per kinetics study.

\section{HPLC analysis}

Plasma concentrations of long acting moxifloxacin was assay by High Performance Liquid Chromatography (Agilent-1100) system was equipped with a model LC-9A (gradient solvent delivery Pump), a model RF-551 fluorescence detector as per method described by Fernandez-Varon et.al. 2006. Chromatographic separation was performed by using $\mathrm{C}_{18}$ column (Supelcosil; $250 \times 4.6 \mathrm{~mm}, 5 \mu)$ at room temperature. Effluent was monitored at excitation wavelength at $296 \mathrm{~nm}$ and emission wavelength of $504 \mathrm{~nm}$. Mobile phase was prepared by mixing buffer and acetonitrile in the ratio of 4:1 [80:20]. Plasma samples were extracted by adding $1000 \mu \mathrm{l}$ plasma and 1000- 
$\mu l$ acetonitrile for precipitation of protein after shaking with vortex shaker for $10 \mathrm{sec}$. followed by centrifugation at $1660 \mathrm{rpm}$ for 10 min. Supernatants fluid were diluted four-fold with $4000 \mu \mathrm{l}$ of $0.067 \mathrm{M}$ disodium hydrogen phosphate buffer ( $\mathrm{pH} 7.5)$ and transferred to HPLC sample vials for estimation.

\section{Pharmacokinetic parameters}

The various pharmacokinetic parameters depicted in table 1 were calculated by software PK solution (version 2.0). Summit research service USA. This programme uses non compartmental model of Pharmacokinetic analysis of long acting moxifloxacin. Interaction of Pharmacokinetic parameters were statistically analyzed using students ttest as per method described by Snedecor and Cochran 1967

\section{Results and Discussion}

The initial plasma concentration of LA moxifloxacin was $0.237 \pm 0.015 \mu \mathrm{g} \cdot \mathrm{ml}^{-1}$ and $0.446 \pm 0.043 \mu \mathrm{g} \cdot \mathrm{ml}^{-1}$ were found at $0.083 \mathrm{~h}$ when LA moxifloxacin given alone and along with meloxicam respectively. The mean peak plasma concentration of LA moxifloxacin was $1.8 \pm 0.077 \mu \mathrm{g} \cdot \mathrm{ml}^{-1}$ achieved at $4 \mathrm{~h}$ when LA moxifloxacin given alone but when given along with meloxicam mean peak serum concentration of LA moxifloxacin was $1.57 \pm$ $0.061 \mu \mathrm{g} . \mathrm{ml}^{-1}$ achieved at $2 \mathrm{~h}$. The lowest plasma drug concentration $0.010 \pm 0.002$ $\mu \mathrm{g} \cdot \mathrm{ml}^{-1}$ and $0.0086 \pm 0.003 \mu \mathrm{g} \cdot \mathrm{ml}^{-1}$ detectable up to $96 \mathrm{~h}$ and $72 \mathrm{~h}$ when LA moxifloxacin given alone and along with meloxicam respectively Mean plasma drug concentration versus time profile depicted in figure 1.

Table.1 Kinetic parameters of Long Acting moxifloxacin after single IM administration (7.5 mg. $\mathrm{kg}^{-1}$ b. wt.) alone and along with meloxicam $(0.5 \mathrm{mg} / \mathrm{kg})$ in male Mehsana goats

\begin{tabular}{|c|c|c|c|}
\hline \multirow{2}{*}{$\begin{array}{c}\text { Pharmacokinetic } \\
\text { parameters }\end{array}$} & \multirow[t]{2}{*}{ Unit } & \multicolumn{2}{|c|}{ Values of Pharmacokinetic parameters } \\
\hline & & $\begin{array}{c}\text { LA moxifloxacin } \\
\text { alone }\end{array}$ & $\begin{array}{c}\text { LA } \\
\text { moxifloxacin } \\
\text { +Meloxicam }\end{array}$ \\
\hline$\beta$ & $\mathrm{h}^{-1}$ & $0.047 \pm 0.002$ & $0.058 \pm 0.004$ \\
\hline $\mathbf{t}_{1 / 2 \beta}$ & $\mathrm{h}$ & $15.194 \pm 0.687$ & $12.297 \pm 0.843^{*}$ \\
\hline$C \max$ & $\mu \mathrm{g} \cdot \mathrm{ml}^{-1}$ & $1.800 \pm 0.077$ & $1.567 \pm 0.061^{*}$ \\
\hline $\operatorname{Tmax}$ & $\mathrm{h}$ & $3.667 \pm 0.333$ & $1.500 \pm 0.224^{*}$ \\
\hline $\mathbf{A} \mathbf{U C}$ & $\mu \mathrm{g} . \mathrm{h} \mathrm{ml}^{-1}$ & $24.117 \pm 1.155$ & $18.533 \pm 0.754^{*}$ \\
\hline AUMC & $\mu \mathrm{g} \cdot \mathrm{h}^{2} \cdot \mathrm{ml}^{-1}$ & $380.40 \pm 4.96$ & $251.183 \pm 5.501^{*}$ \\
\hline MRT & $\mathrm{h}$ & $15.617 \pm 0.523$ & $13.467 \pm 0.726^{*}$ \\
\hline$V_{d(\text { area })}$ & L. $\mathrm{kg}^{-1}$ & $6.829 \pm 0.455$ & $7.249 \pm 0.645$ \\
\hline $\mathbf{V}_{\mathbf{d}(\mathrm{ss})}$ & L.kg ${ }^{-1}$ & $5.06 \pm 0.289$ & $5.66 \pm 0.19$ \\
\hline $\mathrm{Cl}_{\mathbf{B}}$ & L.h ${ }^{-1} \cdot \mathrm{kg}^{-1}$ & $0.307 \pm 0.015$ & $0.408 \pm 0.017^{*}$ \\
\hline $\mathbf{F}$ & $\%$ & $107.97 \pm 9.5$ & $84.271 \pm 3.97^{*}$ \\
\hline
\end{tabular}

Elimination rate constant $(\beta)$, Elimination half life $\left(\mathrm{t}_{1 / 2 \beta}\right)$, Maximum concentration (Cmax), Time at maximum concentration (Tmax), Area under the curve (AUC), area under the first moment of curve (AUMC), Maximum resident time (MRT), Apparent volume of distribution $\mathrm{Vd}\left(\right.$ area), Volume of distribution at steady state $\left(\mathrm{V}_{\mathrm{d}}\right.$ (ss) $)$, Total body clearance ClB, bioavailability $(\mathrm{F})$, 
Fig.1 Comparative semilogrithmic plot of LA moxifloxacin following single dose IM administration (7.5 mg.kg ${ }^{-1}$ b.wt.) alone and in combination with meloxicam (NSAIDs) administered (0.5 mg. $\mathrm{kg}^{-1}$ b.wt.) intramuscularly, in male Mehsana goats

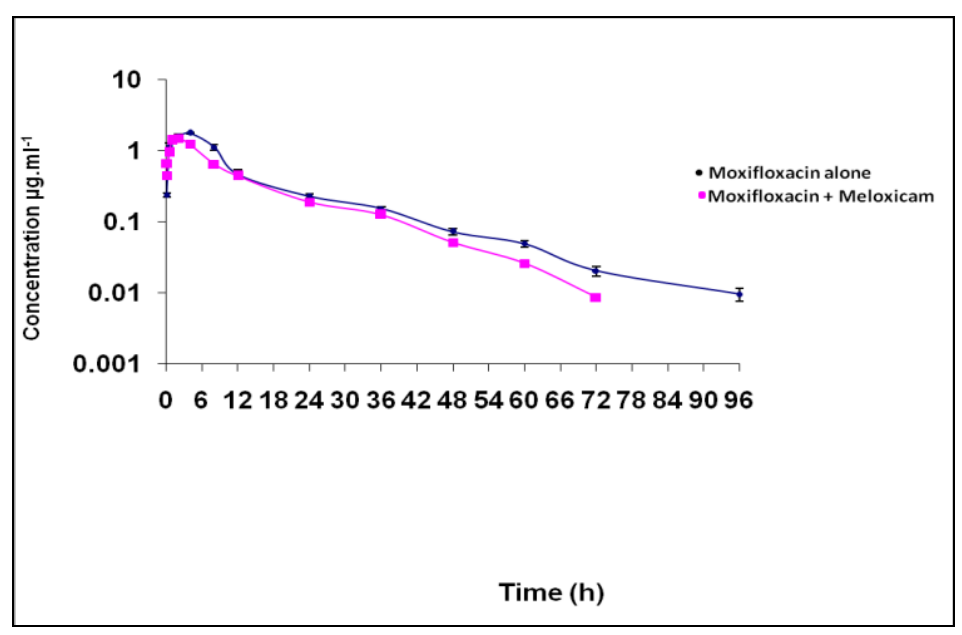

The detailed Pharmacokinetics parameters of long acting moxifloxacin when given alone and concomitant with meloxiacm tabulated in table 1.

In the present study, the mean peak plasma level of LA moxifloxacin level $\left(\mathrm{C}_{\max }\right)$ in goats was observed as $1.57 \mu \mathrm{g} . \mathrm{ml}^{-1}$ at $1.50 \mathrm{~h}\left(\mathrm{~T}_{\max }\right)$ after its single IM administration (7.5 mg. $\mathrm{kg}^{-1}$ b.wt) with concomitant administration of meloxicam (NSAIDs) $0.5 \mathrm{mg} . \mathrm{kg}^{-1}$ intramuscularly. However this observed concentration is approximately equal or slightly lower than the LA moxifloxacin concentration observed when it was administered alone supported with Patel S.D.et al.2011. Drug was detected in plasma at the level of $0.009 \pm$ $0.003 \mu \mathrm{g} \cdot \mathrm{ml}^{-1}$ for up to $72 \mathrm{~h}$ post administration. Goudah (2008) have reported higher peak plasma levels of $2.21 \pm 0.27 \mu \mathrm{g} \cdot \mathrm{ml}^{-1}$ at $1.45 \pm 0.02 \mathrm{~h}$ in lactating ewes after single IM administrations (5 mg.kg ${ }^{-1}$ b.wt.). Similar findings of peak plasma level of $2.16 \pm 0.13 \mu \mathrm{g} \cdot \mathrm{ml}^{-1}$ found at almost in same duration $(1.04 \pm 0.14 \mathrm{~h})$ in healthy male camels was reported following single IM administration $5 \mathrm{mg} \cdot \mathrm{kg}^{-1}$ b.wt. of moxifloxacin (Abd El-Aty et al., 2007).

In this study, therapeutically effective concentration and $\mathrm{C}_{\max }$ attained within $5 \mathrm{~min}$. and $2 \mathrm{~h}$ post administration of LA moxifloxacin. LA moxifloxacin retained above the $\mathrm{MIC}_{90}$ level $\left(0.03-0.12 \mu \mathrm{g} . \mathrm{ml}^{-1}\right)$ from $5 \mathrm{~min}$. to $60 \mathrm{~h}$. This may be due to LA formulation of moxifloxacin, which cover most pathogens (Fernandez-Varon et al., 2005). the value of elimination rate constant as $0.058 \pm 0.004 \mathrm{~h}^{-1}$ was found following single dose IM administrations of LA moxifloxacin (7.5 mg. $\mathrm{kg}^{-1}$ b.wt.) with concomitant administration of meloxicam (NSAIDs) $\left(0.5 \mathrm{mg} \mathrm{kg}^{-1}\right.$ b.wt.) $\mathrm{IM}$ in goats, the observed value is equal to elimination rate constant when LA moxifloxacin administered alone. Goudah (2008), have reported high value of moxifloxacin elimination rate constants $(\beta=0.26$ $\pm 0.13 \mathrm{~h}^{-1}$ ) in lactating ewes with same dose. Similar value of elimination rate constant has been reported by Abd El-Aty et al., (2007) in camels. Value of $\beta$ as $0.34 \mathrm{~h}^{-1}$ has also been reported for moxifloxacin in rabbits (FernandezVaron et al., 2006). The $t_{1 / 2 \beta}$ was found to be $12.297 \pm 0.843 \mathrm{~h}$ were approx equal or slightly lower to alone.

The present study reveals and concluded favorable pharmacokinetic variability of LA moxifloxacin show along with meloxicam, hence it can be concluded that meloxicam interacted with certain pharmacokinetic parameters of long acting moxifloxacin and it may be uses for treatment of infection caused by various organism in goats.

\section{Acknowledgements}

The authors are highly grateful to Sardarkrushinagar Dantiwada Agriculture University, Sardarkrushinagar, North Gujarat, 
India for providing fund and animals facilities for smooth conduction of the research work.

\section{References}

Abd El-Aty, A.M., Goudah, A., Shah, S.S., Shin, H.C., Shimoda, M. and Shim, J.H. 2007. Pharmacokinetic variables of moxifloxacin in healthy male camels following intravenous and intramuscular administration, J. Vet. Pharmacol. Therapeutics, 30: 586-591.

Dumka, V.K., Singh, H. and Srivastva, A.K. 2008. Disposition kinetics and urinary excretion of levofloxacin on concomitant administration with meloxicam in cross breed Calves Environ. Toxicol. Pharmacol., 26: 56-60.

Euller-Ziegler, L. and Velicitat, P. 2001. Meloxicam: A review of its pharmacokinetics, efficacy and tolerability following intramuscular administration, Inflammation Res., 50: S5-S9.

Fernandez-Varon, E., Bovaira, M.J., Espuny, A., Escudero, E., Vancraeynest, D. and Carceles, C.M. 2005. Pharmacokineticpharmacodynamic integration of Moxifloxacin in rabbits after intravenous, intramuscular and oral administration. $J$. Vet. Pharmacol. Therapeutics, 28: 343348.

Fernandez-Varon, E., Villamayor, L., Escudero, E., Espuny, A. and Carceles, C.M. 2006. Pharmacokinetics and milk penetration of moxifloxacin after intravenous and subcutaneous administration to lactating goats. The Vet. J., 172: 302-307.

Muller, F.O., Middle, M.V., Schall, R., Terblanche, J., Hundt, H.K.L. and Groenewoud, G. 1997. An evaluation of the interaction of meloxicam with frusemide in patients with compensated chronic cardiac failure. British J. Clin. Pharmacol., 44: 393-98.

Noel, A.R., Bowker, K.E., MacGowan, A.P. 2005. Pharmacodynamics of moxifloxacin against anaerobes studied in an in vitro pharmacokinetic model. Antimicrob. Agents Chemother., 49: 4234-4239.

Pardillo, F.E.Fe., Burgos, J., Fajardo, T.T. Cruz, E.D., Abalos, R.M., Paredes, R, M.D., Andaya, C.E.S. and Gelber, R.H. 2008. Powerful bactericidal activity of moxifloxacin in human leprosy. Antimicrobial Agents and Chemother., 52(9): 3113-3117.

Sadariya, K.A., Gothi, A.K., Patel, U.D., Gohil, P.A., Jain, M.R., Bhavsar, S.K. and Thaker, A.M. 2011. Effect of moxifloxacin administration on pharmacokinetics of tolfenamic acid in rats. Braz. Arch. Biol. Technol., 54(4): 739-744.

Snedecor, G.W. and Cochran, W.G. 1667. Statistical Method, Iowa State University Press, Ames USA.

Sullivan, J.T., Woodruff, M., Lettieri, J., Agarwal, V., Krol, G.J., Leese, P.T., Watson, S., and Heller, A.H. 1999. Pharmacokinetics of a once daily oral dose of moxifloxacin (Bay 12-8039), a new enantiomerically pure 8methoxy quinolone. Antimicrobial Agents and Chemother., 43(1): 2793-2797.

Effects of Concurrent Administration of Meloxicam on Pharmacokinetic Parameters of Enrofloxacin in Turkeys. J. Bioanal. Biomed., 3: 108-112.

Deleforge, Thomas, E., Davot, J.L. and Boisrame, B. 1994. A field evaluation of the efficacy of tolfe namicacid and Oxytetracycline in the treatment of bovine respiratory disease. J. Vet. Pharmacol. Therapeutics, 17: 4347.

Goudah, A. 2007. Disposition kinetics of moxifloxacin in lactating ewes. The Vet. J., 178: 282-287.

\section{How to cite this article:}

Kumari Anjana, S.K. Mody, R.K. Nirala and Archana Kumari. 2017. Effect of Meloxicam on Pharmacokinetics of Long Acting Moxifloxacin in Goats. Int.J.Curr.Microbiol.App.Sci. 6(3): 11041108. doi: https://doi.org/10.20546/ijcmas.2017.603.127 